\title{
ISLAMISASI DAN DAKWAH ALKHAIRAAT DALAM MASYARAKAT MAJEMUK DI KOTA MANADO TAHUN 1947-1960
}

Lisa Aisyiah Rasyid

IAIN Manado

\begin{abstract}
Abstrak
Penelitian ini berusaha menjelaskan proses Islamisasi di Manado di mana dakwah Alkhairaat sebagai objeknya, karena dianggap memiliki peran penting dalam proses Islamisasi tersebut, terutama dalam mengimbangi dan membendung arus missionaris pada masa kolonial. Penelitian ini merupakan penelitian sejarah yang dibatasi dari tahun 1947-1960. Pembatasan ini dikarenakan pada tahun 1947 pendidikan dan dakwah Akhairaat mulai menjamur dan turut mewarnai semaraknya penggunaan ruang di Manado pascakolonial. Pada tahun 1960, dakwah Alkhairaat semakin terlihat dengan didirikannya pesantren Alkhairaat, yang terletak di Komo Luar, sebagai pesantren pertama di Manado. Penggunaan metode sejarah: heuristik, verifikasi, interpretasi dan historiografi, tentunya menjadi keharusan dalam penelitian ini guna mendapatkan karya ilmiah yang bersifat sejarah kritis. Hasil penelitian kemudian menunjukkan proses Islamisasi dan perkembangan Islam di Manado pada pertengahan abad ke-20, tidak terlepas dari peran penting Alkhairaat di bidang dakwah dan pendidikan. Sejak tahun 1947 mcgf eadrasah Alkhairaat telah menjamur di Manado, hingga pada tahun 1960 berdirilah pesantren Alkhairaat pertama di Komo Luar Manado. Pada rentan waktu yang bersamaan juga terjadi perubahan sosial-budaya masyarakat Islam Manado yang menonjolkan sikap tawasuth (moderat), tasammuh (toleransi), tawazzun (seimbang), dan ta'addul (adil), yang kesemuanya mencerminkan nilai-nilai agama.
\end{abstract}

Kata Kunci: Islamisasi, dakwah Alkhairaat, masyarakat majemuk, Kota Manado

\section{Islamization and A1-Khairat Da'wah in Compound Society in the city of Manado between 1947-1960}

This research tries to explain the process of Islamization in Manado where the Alkhairaat Da'wah as the object, as it is viewed to have important role in the process, especially to offset and stem the missionary during the colonial era. This research is a historical one 
limited to the 1947-1960 period of time. The limitation is due to the fact that in 1947, the Alkhairat education and da'wah started blossoming and put color in public spaces in the postcolonial Manado. In 1960, the Alkhairaat da'wah became more visible for the establishment of their pesantren located in Komo Luar as the first pesantren in Manado. Heuristics, verification, interpretation, and historiography are essential methods in order to achieve a critical history. The research finding then shows that Islamization process and Islamic progress in Manado in mid 20 AD can be separated from the important role of Alkhairaat in da'wah and education. In the same period of time, Socio-cultural changes occur among Islamic society in Manado that promote views of tawasuth (moderat) tasammuh (tolerant), tawazzun (balance), and taaddul (fair) which reflect the religion views.

Keywords: the Alkhairaat da'wah, Ccompound society, the City of Manado

\section{A. Pendahuluan}

Dalam proses Islamisasi, dakwah merupakan kegiatan menyampaikan agama Islam dari seseorang kepada orang lain ${ }^{1}$ dengan tujuan untuk mengubah individu dan masyarakat ke arah kehidupan yang lebih baik. Tujuan dakwah demikian sesuai dengan tujuan komunikasi persuasif, yakni adanya perubahan situasi orang lain atau mengubah/ mempengaruhi kepercayaan, sikap, dan perilaku seseorang sehingga bertindak sesuai dengan apa yang diharapkan oleh komunikator. ${ }^{2}$ Secara historis, hal ini juga telah dicapai Rasullah saw dalam melaksanakan dakwah ilallah kepada segenap umat manusia, pada periode awal Islamisasi.

Dakwah Islam dalam sejarahnya dijelaskan Rasulullah tidak bersifat agresif, yakni seolah-olah orang harus bisa masuk Islam. Berdakwah bukan berarti memaksa, karena Islam bukan agama paksaan. Islam adalah agama yang benar, sedangkan yang benar dan salah adalah jelas perbedaannya.

Dakwah yang demikian, juga nampak dalam gerakan dakwah organisasi Alkhairaat

M. Ali Aziz, Ilmu Dakwah (Jakarta: Prenada Media, 2004), hlm. 10

2 Asep Syamsul M. Romli, Komunikasi Dakwah: Pendekatan Praktis (Bandung: Mizan, 2014), h. 14 di Manado. Gerakan Alkhairaat di bidang dakwah memiliki kontribusi yang sangat besar, terutama terhadap masyarakat di wilayah Kota Manado dalam mengimbangi dan membendung arus missionaris pada masa kolonial.

Pada masa itu, selain menjadi pusat administrasi pemerintahan, Manado juga merupakan pintu masuk pertama dan salah satu pusat pengembangan Kristen ke pelosok Minahasa dan sekitarnya. ${ }^{3}$ Sehingga tidak heran jika mayoritas penduduk di kota ini adalah penganut agama Kristen, yang terus mengalami perkembangan dan perbaikan baik dari segi ritual maupun sarana dan prasarana yang menunjang kegiatan keagamaannya. Sementara umat Islam tergolong minoritas dengan pemahaman agama yang saat itu masih minim karena kurangnya pendidikan dan pengajaran Islam secara intens dan terusmenerus.

Realitas keberagamaan yang tidak seimbang itu, rupanya mengundang kekhawatiran Habib Sayyid Idrus bin Salim Aljufriy, selanjutnya disebutnya Guru Tua. Karenanya pada tahun 1935, Guru Tua mengutus beberapa orang santrinya yang telah tamat Basri Amin, Islam di Utara Sulawesi: Sejarah, Tradisi dan Dinamikanya (Jakarta: Gramedia, 2005), hlm. 58 
untuk berdakwah di Manado. Perkembangan dakwah Alkhairaat hingga ke wilayah ini, telah banyak memberikan kontribusi kepada masyarakat Muslim di Manado. Hingga pada tahun1947, pendidikandandakwahAlkhairaat di Manado telah turut mewarnai semaraknya penggunaan ruang oleh masyarakat Muslim pascakolonial. Sebelumnya telah hadir pula gerakan sosial organisasi Islam di Manado, seperti Serikat Islam (SI) tahun 1920 dan Muhammadiyah tahun 1934. Baik Alkhairaat, SI dan Muhammadiyah, ketiganya berupaya untuk mengimbangi arus missionaris Kristen terutama oleh lembaga pendidikan zending yang sudah berlangsung sejak masa Kolonial Belanda. ${ }^{4}$ Terbukti SI mendirikan sekolah Yayasan Cokroaminoto tahun 1926, Muhammadiyah mendirikan sekolah Muhammadiyah tahun 1937, dan Alkhairaat mendirikan Madrasah Alkhairaat tahun 1947 di Kampung Islam.

Penulis dalam melakukan kajian terhadap proses Islamisasi dan dakwah Alkhairaat ini menggunakan pendekatan sejarahsosial, yang dimaksudkan untuk melakukan eksplanasi sejarah terhadap gerakan dakwah Alkhairaat yang terindikasi mampu membawa progres terhadap kehidupan sosial-keagamaan masyarakat majemuk di Manado dengan latar belakang yang berbeda dan etnosentris. Kajian sejarah sosial ini, hanya dibatasi pada sejarah gerakan sosialkeagamaan yakni dakwah dan bukan dalam bentuk sejarah total. Karena sebagaimana dikatakan Kuntowijoyo, sejarah sosial dapat pula mengambil tema tertentu dengan spesialisasi mengenai hal-hal yang sebagian

\footnotetext{
Ada dua lembaga Kristen yang bertugas saat itu, yaitu: Nederlands Zending Genootschap (NZG) tahun 1829 dan Indische Kerk (IK) tahun 1876. Ilham, "Agama, Perubahan Sosial dan Penggunaan Ruang di Manado, dari Kolonial ke Pasca Kolonial, dalam www.geocities.ws/konferensinasionalsejarah/ilham.pdf. diakses tanggal 19 Maret 2016.
}

saja dari kajian yang mengambil fakta sosial. ${ }^{5}$ Secara lebih jelas Hect mengatakan bahwa pembahasan aspek-aspek tertentu, terutama yang non-politik, sudah cukup memadai untuk dapat disebut sebagai sejarah sosial. ${ }^{6}$ Progres kehidupan sosial-keagamaan masyarakat majemuk di Manado merupakan fakta sosial yang menjadi fokus penelitian ini dengan mengaitkannya pada dakwah Islam Alkhairaat.

Penegasan kata dakwah Alkhairaat dalam penelitian ini dimaksudkan untuk mengkaji tentang dakwah sebagai "aktivitas mempengaruhi" dalam proses Islamisasi, bukan dakwah sebagai "disiplin ilmu pengetahuan". Karena secara substansial filosofis, dakwah merupakan proses rekayasa sosial menuju tatanan masyarakat ideal sesuai dengan pesan-pesan Tuhan. ${ }^{7}$ Adapun konsep masyarakat yang dimaksudkan dalam penelitian adalah masyarakat majemuk. Clifford Geertz mendefinisikan masyarakat majemuk sebagai masyarakat yang terbagi dalam subsubsistem yang kurang lebih berdiri sendirisendiri, di mana masing-masing sub sistem terikat oleh ikatan-ikatan yang bersifat primordial. $^{8}$

Berdasarkan beberapa teori di atas, menunjukkan bahwa sasaran utama dakwah adalah perubahan sosial. Dakwah Islam Alkhairaat sebagai agent of change bagi masyarakat Manado, berupaya memberikan perubahan nilai serta arah dan corak ideal

Kuntowijoyo, Metodologi Sejarah, Edisi Kedua (Yogyakarta: Tiara Wacana, 2003), hlm. 75

6 Dikutip dari sebuah "Makalah Disertasi” oleh Maftuh, Lembaga Pendidikan Al-Khairiyah di Banten (1916-1942): Pendekatan Sejarah Sosial (Yogyakarta: PPS UIN Su-Ka Yogyakarta, 2015), hlm. 21

7 Siti Uswatun Khasanah, Berdakwah dengan Jalan Debat Antara Muslim dan Non Muslim (Yogyakarta: STAIN Purwokerto Press \& Pustaka Pelajar, 2007), hlm. 3

8 Nasikun, Sistem Sosial Indonesia, Cet. Ke-12 (Jakarta: PT. Raja Grafindo Persada, 2003), hlm. 33 
tatanan masyarakat baru yang sesuai dengan tujuan dakwah Islam. Hal ini mengindikasikan adanya perubahan sosial yang sifatnya evolusi (dari yang sederhana ke yang kompleks). Teori ini lebih dikenal dengan istilah teori "Evolusi Model Spencer"9 yang menurut ungkapan spencer sendiri, perubahan dari "homogenitas yang tidak koheren" ke "heterogenitas koheren".

Sebagaimana telah disinggung di atas, kajian ini merupakan salah satu kajian sejarah sosial dengan penggunaan metode sejarah. Pertama, heuristik sebagai proses pengumpulan data primer dan data sekunder. Sumber primer dalam konteks kajian ini mengacu pada data yang menunjukkan aktivitas keagamaan masyarakat muslim Manado, dan dakwah Alkhairaat pada tahun 1947-1960. Sedangkan sumber sekunder dalam penelitian ini mencakup semua sumber kepustakaan baik buku, jurnal, koran, dan hasil penelitian lain yang relevan dengan objek kajian.

Kedua, kritik (verifikasi) sumber. Pada tahap ini, peneliti menguji kebenaran dan ketepatan (akurasi) dari data yang berkaitan dengan proses Islamisasi dan dakwah Alkhairaat di Manado, agar nampak hubungan antara proses Islamisasi, dengan perjuangan dakwah Alkhairaat di Manado pada tahun 1947-1960. Ketiga, adalah interpretasi dengan cara menganalisis fakta sejarah. Penelitian ini termasuk kategori penelitian kualitatif eksplanatif, ${ }^{10}$ yakni suatu penelitian yang berusaha melihat hubungan di antara data (kualitatif) yang dikumpulkan. Kemudian dilakukan eksplanasi sehingga

Peter Burke, Sejarah dan Teori Sosial, Cet. Ke-2 (Jakarta: Yayasan Obor Indonesia, 2003), hlm. 198

10 Lihat Heribertus Sutopo, Pengantar Penelitian Kualitatif, Dasardasar Teoritis dan Praktis (Surakarta: Pusat Penelitian UNS, 1988), hlm. 16. benar-benar tampak ada hubungan antara pengembangan masyarakat yang dilakukan oleh Alkhairaat melalui dakwahnya dengan perubahan sosial masyarakat Muslim di Manado. Keempat, adalah historiografi yaitu penafsiran dan penyajian hasil analisis fakta-fakta sejarah di lapangan. Historiografi digunakan untuk mengangkat dan menguraikan makna dari gerakan dakwah Alkhairaat sebagai sebuah proses Islamisasi dalam rangka mengembangkan kualitas dan kuantitas umat Islam, sekaligus membendung arus kristenisasi di Manado.

Berdasarkan eksplanasi historis di atas, maka penting kiranya untuk mengkaji lebih lanjut hal-hal terkait dakwah Alkhairaat dan kontribusinya dalam perkembangan Islam di Manado. Berbagai hal dimaksud mencakup permasalahan tentang bagaimana struktur kehidupan sosial-keagamaan masyarakat Islam di Manado, apa strategi dakwah Alkhairaat terhadap masyarakat tersebut, kemudian adakah progress yang terlihat setelah mereka menerima dan terbuka dengan dakwah Islam yang dibawa oleh Alkhairaat.

\section{B. Potret Sosial Budaya Masyarakat Manado Pertengahan Abad XX}

Sebagai ibukota provinsi Sulawesi Utara, Manado dikenal oleh masyarakat luas sebagai kota religius, negeri yang diberkati. Meskipun demikian, Manado masih menyimpan bom waktu, yakni "gaya hidup hedonis". ${ }^{11}$ Agama yang dianut masyarakat kota Manado adalah Kristen Protestan, Katolik, Islam, Hindu, dan

\footnotetext{
Gaya hidup hedonis yang dimaksud, di antaranya: semarak orang mabuk, pelacuran, jalur beredar narkoba/ekstasi, pembunuhan hanya alasan sepele, perceraian, broken home, kumpul kebo, politik uang dianggap biasa-biasa saja, pergaulan bebas, berfoya-foya, dan sebagainya. Benedicta J. Mokalu, “Gaya Hidup Prahara Karakter Kota Manado", Jurnal LPPM Bidang Ekososbudkum, Volume 1 Nomor 1 Tahun 2014, hlm. 41.
} 
Budha. Namun mayoritas adalah penganut agama Kristen Protestan dan Katolik. Belakangan kota ini dikenal dan digaungkan sebagai daerah miniatur kerukunan umat beragama di Indonesia. ${ }^{12}$ Namun sebelumnya tidaklah demikian hingga berakhirnya masa kolonial. ${ }^{13}$

Lahirnya berbagai gerakan sosial organisasi Islam di Manado, serta Hengkangnya kolonial, telah membawa pengaruh berlangsungnya proses perubahan sosial budaya masyarakat Manado. Pada aspek keagamaan misalnya, dominasi Kristen Protestan yang terjadi masa kolonial bergeser dengan terciptanya "ruang" yang lebih terbuka untuk agama lain terutama Islam.

Pascakolonial, aktivitas keagamaan lebih menekankan aspek "kualitas" beragama dalam arti menvisualisasikannya dalam simbol agama, baik itu ritual keagamaan, tempat ibadah, maupun aktivitas sosial lainnya. ${ }^{14}$ Sejak tahun 1957, kegiatan ritual keagamaan Islam seperti perayaan Maulid Nabi, mulai ramai dilaksanakan. Pada tahun tersebut, perayaan Maulid Nabi ramai dilaksanakan di bioskop "Majestik" Manado, kampung Arab, dan Sario. ${ }^{15}$

Penggunaan ruang untuk pihak Islam terlihat lebih luas lagi sejak Peristiwa Permesta (Perlawanan Rakyat Semesta) tahun 1958. Banyaknya orang "pusat" yang ditugaskan ke Manado, baik militer maupun tenaga administrasi pemerintahan sehubungan dengan penanganan Permesta, hal ini mendo-

\footnotetext{
12 Nono Stevano Agustinus Sumampouw, "Menyatukan dan Memecah Belah: Wacana dan Praktek Identitas Sosial Orang Manado", Tesis (Yogyakarta: PPS Fakultas Ilmu Budaya UGM, 2013), hlm. 1.

13 Ilham, "Agama, Perubahan Sosial dan Penggunaan Ruang di Manado, dari Kolonial ke Pasca Kolonial", dalam www.geocities. ws/konferensinasionalsejarah/ilham.pdf, diakses tanggal 19 Maret 2016.

14 Ibid.

15 Ibid.
}

rong banyaknya migrasi dari berbagai daerah dengan berbagai kepentingan. Sejak saat itulah warga kota yang beragama Islam terus meningkat pesat, seiring dengan menguatnya pengaruh kelompok Islam di bidang sosial politik. Pertambahan penduduk beragama Islam pun menyebar ke berbagai bagian kota. Pusat-pusat ekonomi dan beberapa perkampungan baru, menjadi alternatif pemukiman. ${ }^{16}$

Data penduduk hingga tahun 1970 memperlihatkan jumlah persentase Kristen Protestan 62.10\% diikuti Islam 31.30\%, Katolik 5.02\% dan sedikit Budha dan Hindu. Meningkatnya jumlah umat Islam di Manado, berdampak pada peningkatan penggunaan ruang untuk sarana peribadatan seperti masjid dan mushalah. ${ }^{17}$

Pada aspek pendidikan, yayasan pendidikan Islam seperti Muhammadiyah dan Cokroaminoto, telah mewarnai proses pendidikan di Manado. Tetapi keduanya lebih banyak memusatkan perhatiannya pada sekolah-sekolah umum, sebagai imbangan terhadap misi dan zending yang bertebaran di seluruh pelosok Manado. Sementara perhatiannya terhadap pesantren dan madrasahmadrasah yang Diniyyah, hampir tidak terlihat. $^{18}$

Pertumbuhan madrasah-madrasah Diniyah di Manado baru terlihat pada pertengahan abad ke-20, ketika Lembaga Pendidikan Islam Alkhairaat mulai memasuki Sulawesi Utara. Tahun 1947 berdiri Madrasah Alkhairaat yang pertama di Kampung Arab, Manado. Lalu Tahun 1948 dibangun Madrasah pertama diGirian Bawah, Minahasa. Kemudian

\footnotetext{
16 F.E.W. Parengkuan, et al., Sejarah Kota Manado 1945-1979 (Jakarta: Depdikbud, 1986), hlm. 30.

17 Laporan Bimas Islam Kementrian Agama Kota Manado.

18 Hadat L.A., "Sejarah Islam di Sulawesi Utara- Part 4", dalam http://artfalsafah.blogspot.co.id/2013/05/html, diakses tanggal 30 Mei 2016.
} 
tahun 1949 berdiri Madrasah pertama di Bolaang Mongondow, di Jambusarang-Bolang Itang. Sebelumnya, Madrasah Alkhairaat juga telah didirikan di Kabupaten Gorontalo, di Desa Lemito-Popayato. ${ }^{19}$

Tahun 1960, Alkhairaat mendirikan sebuah pesantren di Kampung Komo. Sejak saat itu, pembangunan pesantren di Manado mulai menjamur. Tercatat hingga tahun 1996, Manado telah memiliki 4 jumlah pesantren yang masih lestari hingga saat ini. Dapat dikatakan, gerakan keagamaan Alkhairaat padapertengahanabadXXsemakinmenambah semarak dan mempercepat pertumbuhan dan perkembangan Islam yang tidak saja di Kota Manado dan sekitarnya, bahkan sampai ke pelosok-pelosok dan daerah-daerah Sulawesi Utara pada umumnya.

\section{Gerakan Dakwah Alkhairaat di Manado}

Jika menilik potret dan corak keberagamaan dari beberapa provinsi seperti: Sulawesi Tengah, Gorontalo, Sulawesi Utara (Manado), Maluku, Maluku Utara dan Papua, tidak bisa dipisahkan dari pengaruh dakwah Guru Tua dan diaspora dari ratusan murid yang tersebar pada wilayah-wilayah tersebut. ${ }^{20}$

Alkhairaat, dalam aktivitas dakwahnya berafiliasi kepada mazhab Sunni - dengan NU sebagai partner-nya - tapi progresif dalam merespon problematika sosial politik keagamaan dan kebangsaan. Karenanya, nilai-nilai Islam yang disampaikan adalah berdasarkan ideologi Sunni.

Kecenderungan dakwah Alkhairaat yang berorientasi pada perbaikan kehidupan

\footnotetext{
19 Wawancara dengan KH. Sofyan Lahilote (Mantan Komwil Alkhairaat Sulut dan Mantan Ketua Pengadilan Tinggi Agama Manado), di Rumah, Jln. Manguni 2 Kompleks Masjid Al-Djufri, Malendeng, Tikala, Manado, Tanggal 6 Maret 2016.

$20 \quad$ Ibid., hlm. 215
}

keagamaan masyarakat Muslim di Manado, melalui pendekatan evolusioner daripada pendekatan revolusioner yang radikal, membuat keberadaan dakwah Alkhairaat pada pertengahan abad XX diterima secara antusias baik oleh kalangan Arab maupun pribumi, meskipun saat itu kota Manado masih berada dalam bayang-bayang dominasi missionaris. Terbukti ketika Alkhairaat mendirikan sebuah madrasah pada tahun 1947 di Kampung Arab, masyarakat turut berpartisipasi baik secara moril maupun materil. ${ }^{21}$ Bahkan pembangunan pesantren Alkhairaat (1960) Komo pun, semua atas bantuan masyarakat, mulai dari bangunan, hingga tanah tempat berdirinya pesantren tersebut, merupakan waqaf dari masyarakat. ${ }^{22}$

Tampaknya, keberadaan madrasah dan pesantren Alkhairaat di Manado pada saat itu, selain dimaksudkan untuk pencerahan umat, juga untuk mengimbangi dan membendung arus missionaris Kristen, supaya tidak mendominasi peta dakwah di wilayah tersebut. Dengan demikian keberadaan Alkhairaat tidak dimaksudkan untuk menyaingi missionaris Kristen saat itu. Sehingga tidak heran jika Alkhairaat dalam aktivitas dakwahnya, hingga saat ini, hampir tidak ditemukan benturan atau konflik antarumat Kristen dengan Abna' alKhairaat $^{23}$ dan keluarga besar Alkhairaat

21 Wawancara dengan Mashar Kinontoa (Seksi Bidang Pendidikan Agama Komda Manado / Kepsek MI Alkhairaat Kampung Arab), di Rumah, Jl. Cokroaminoto Kompleks SMA Alkhairaat Kampung Arab, Tuminting, Manado, Tanggal 24 Februari 2016.

Ibid.

23 Abnaul Khairaat secara harfiah berarti anak-anak Alkhairaat, yakni anak-anak yang lahir dari Alkhairaat. Dalam perkembangannya, istilah ini kemudian diartikan sebagai pengikut Alkhairaat, baik pengurus, anggota, maupun para lulusan madrasah-madrasah dan angggota majelis taklim Alkhairaat, atau bahkan simpatisan Alkhairaat. Wawancara dengan Zubair Lakawa (Pimpinan Pondok Pesantren Alkhairaat Mapanget Barat-Manado), di Kantor Madrasah Aliyah Ponpes Alkhairaat Mapanget Barat, Jl. Koka, Mapanget Barat, Kota 
secara keseluruhan.

Dakwah Alkhairaat yang selalu berpegang pada prinsip-prinsip moderat dan toleran, membuat masyarakat di Manado yang majemukitu bersikap transparan dan antusias dalam menerima dan mengimplementasikan apa yang telah disampaikan. Hal ini bisa terlihat pada aktivitas keagamaan yang dilakukan pada sebagian besar jamaah (Islam) di Manado yang mencerminkan kegiatan-kegiatan ritual keagamaan yang diperkenalkan oleh Alkhairaat mulai dari pembacaan barzanji yang sering dilaksanakan setiap malam Jumat; pembacaan maulid diba' setiap tahun untuk memperingati Maulid Nabi; pembacaan rawatib al-haddad setiap malam Kamis; kegiatan kesenian sara'samra' setiap malam Jumat ba'da isya; haul Guru Tua yang sering dilaksanakan setiap tahun dan lain-lain, yang sering dilaksanakan secara rutin di beberapa wilayah yang ada di Manado.

Keberhasilan Alkhairaat dalam mendakwahkan ajaran Islam ini juga terbukti melalui berdirinya beberapa Madrasah Alkhairaat baik yang berbentuk pondok pesantren maupun non-pesantren - yang kesemuanya tentu berbasis pendidikan Islam yang pelajaran-pelajarannya juga didominasi dengan pengetahuan agama Islam - seperti MA Alkhairaat dan Madrasah-Madrasah Diniyah yang tersebar di banyak wilayah Kota Manado. Keberhasilan ini tentu bukan sesuatu yang biasa-biasa saja, mengingat realitas masyarakat Manado yang majemuk dengan gaya hidup yang hedonis dan didominasi oleh suku Minahasa, sebagai suku asli orang Manado.

Suku Minahasa, sangat berpegang teguh pada kepercayaan agama Kristiani, kecuali

Manado, Tanggal 18 Februari 2016. mereka yang pindah agama (Islam) karena hidayah maupun karena pernikahan dengan seorang Muslim. Sebagian besar dari mereka, mencari penghidupan dari pohon aren atau dalam bahasa melayu Manado dikenal dengan sebutan "pohon saguer". Buah dari pohon ini diolah menjadi minuman keras untuk kemudian dijual, dan sebagiannya dikonsumsi secara pribadi. Budaya belanda yang menyuguhkan minuman keras dan permainan judi dalam setiap ceremony, sangat cepat mempengaruhi kehidupan masyakarat Manado sehingga lambat laun menjadi bagian dari tradisi lokal masyarakat setempat.

Kondisi yang demikian, menjadi tantangan tersendiri bagi Alkhairaat, serta membutuhkan kesabaran dan pendekatanpendekatan juga strategi yang tidak biasa dalam mengajak dan mengajarkan mereka tentang syariat Islam. Apalagi jika melihat perkembangan dakwah Alkhairaat hingga tahun 1960 yang ditandai dengan berdirinya sebuah pesantren Alkhairaat di pusat Kota Manado, menunjukkan kontribusi Alkhairaat dalam bidang dakwah tersebut sangat mempengaruhi perkembangan dan religiusitas umat Islam di wilayah yang terkenal dengan sebutan "Menara Seribu Gereja”.

Dalam aktivitas dakwahnya, Alkhairaat secara keseluruhan, merepresentasikan diri sebagai pengawal tradisi Sunni. Sebagaimana ditegaskan di dalam Anggaran Dasarnya, bahwa "...Alkhairaat berasaskan Islam dan berhaluan Ahlussunnah wal Jama'ah dengan berpaham Asy'ariyah dan bermadzhab Syafi'i". ${ }^{24}$ Dari sini, maka lahirlah beberapa tradisi yang dipraktikkan Abnaul Khairaat di antaranya: tahlilan, yasinan, deba'an, barzanji,

\footnotetext{
Gani Jumat, Nasionalisme Ulama: Pemikiran Politik Kebangsaan Sayyid Idrus bin Salim Aljufry, 1891-1969 (Jakarta: Kementrian Agama RI, 2012), hlm. 104
} 
mencium tangan ustad (guru), ziarah makam para wali, manaqib, dan khaul.

Alkhairaat juga menyiapkan $d a^{\prime} i$ pada peringatan hari-hari besar Islam, khutbah Jumat, dan majelis taklim yang dilaksanakan di masjid-masjid maupun di rumahrumah. Khusus pada bulan Ramadhan para da'i diterjunkan ke daerah-daerah untuk menyampaikan ceramah Ramadhan. Selain itu, Alkhairaat bekerja sama mengantisipasi dan menyukseskan program pemerintah baik pusat maupun daerah, dalam menyampaikan bahasa agama. ${ }^{25}$

Menurut hemat penulis, kepiawaian para tokoh Alkhairaat dalam membangun komunikasi dengan pemerintah dan para pendeta serta umat agama lain, merupakan kuncisukses dalam strategidakwah Alkhairaat di Manado. Prinsip-prinsip moderat dan toleran menjadi pegangan mereka dalam mendakwahkan Islam di Manado. Tidakheran jika Alkhairaat dalam perkembangannya, menjadi organisasi yang memiliki ikatan emosional kuat dengan masyarakat Islam di Manado. Mereka mempunyai rasa memiliki yang tinggi terhadap Alkhairaat, sehingga menjadi bagian dari Abnaul Khairaat.

\section{Progresivitas Dakwah Alkhairaat terhadap Perkembangan Umat Islam di Manado}

Dakwah ialah aktualisasi imani yang dimanifestasikan dalan suatu sistem kegiatan manusia untuk melakukan proses rekayasa sosial melalui usaha mempengaruhi cara berperasaan, berpikir, bersikap dan berperilaku sesuai dengan tuntunan sosial dan norma ajaran agama Islam. ${ }^{26}$ Dakwah diharapkan

Wawancara dengan Sukri Mararo (Sekretaris Komwil Alkhairaat Sulut), di Rumah, Jl. Jati, Kampung Islam, Tuminting, Manado, Tanggal 5 Mei 2016.

26 Miftah Faridl dalam A. Darun Setiady, Revitalisasi Peran PI dalam dapat membawa perubahan dalam tatanan hidup masyarakat agar sesuai dengan nilainilai Islam.

Urgensi dakwah dalam proses Islamisasi dan pembaharuan Islam di Nusantara, tentu tidak lepas dari kreativitas muballigh dan tokoh-tokoh Islam yang turut mengambil peran penting dalam proses Islamisasi dan perkembangan Islam. Mereka ini tersebar diseluruh pelosok Nusantara.

Pada praktiknya, dakwah Islam dilakukan oleh para pelaku dakwah melalui sejumlah lembaga/ormas keagamaan ataupun secara individual. Meski dalam beberapa kasus dakwah individual cukup berperan, namun dakwah melalui lembaga biasanya lebih luas jangkauannya karena tersedianya perangkat organisasi yang masif dan terstruktur, dari pusat ke daerah. Alkhairaat misalnya, memiliki jaringan pendidikan dan dakwah yang cukup banyak. Tercatat hingga tahun 1960-an, Alkhairaat telah memiliki 420 cabangyang tersebar di enam Provinsi, yaitu: ${ }^{27}$

- $\quad$ Provinsi Sulawesi Tengah 338 cabang

- $\quad$ Provinsi Sulawesi Utara 41 cabang

- Provinsi Sulawesi Selatan 6 cabang

- Provinsi Maluku 28 cabang

- Provinsi Irian Barat 1 cabang

- Provinsi Kalimantan Timur

$6 \quad$ cabang

Persebaran cabang Akhairaat yang banyak itu, telah berperan penting dalam proses Islamisasi dan perkembangan Islam di Kota Manado. Secara historis, fakta seperti ini tentu tidak sulit dipahami, karena dakwah dan

Pemberdayaan Umat (Bandung: Mizan, 2006), hlm. 243.

27 H. Ahmad Bachmid, Sang Bintang dari Timur: Sayyid Idrus AlJufri, Sosok Ulama dan Sastrawan (Jakarta: Studia Press, 2007), hlm. 53 
pendidikan Islam menjadi instrumen penting dalam proses perkembangan Islam dan transmisi gagasan pembaharuan bahkan jauh sebelum bangsa Eropa, termasuk Belanda datang dengan konsep kolonialismenya. Rasi'in menjelaskan bahwa pendidikan Islam dan dakwah berjalan berkembang seiring dengan dakwah dan penyebaran Islam itu sendiri, baik di kalangan masyarakat maupun istana. Pendidikan Islam dan dakwah pada saat itu mengambil bentuk halaqah, dan tatap muka perorangan baik di masjid, mushalla maupun di pesantren-pesantren. ${ }^{28}$

Adanya peran Alkhairaat dalam bidang dakwah dan pendidikan, telah memberikan pengaruh dalam pembangunan spiritual, bagi terciptanya pola pikir, sistem pengetahuan, sistem sosial dan sistem perilaku umat Islam di Manado, sehingga berdampak pada perubahan sosial budaya masyarakat Islam Manado yang mencerminkan nilai-nilai agama. Hal ini terbukti adanya perubahan yang terjadi tanpa paksaan, khususnya dalam peningkatan pengamalan ajaran Islam, yang ditandai dengan adanya peningkatan intensitas pelaksanaan ibadah dan ritualritual keagamaan, mejamurnya pendidikan Madrasah, dan berdirinya pesantren Akhairaat di Komo Luar, Manado. Ciri khas santri yang sederhana dan memiliki solidaritas yang tinggi yang melekat pada Abnaul Khairaat, juga telah berdampak pada perubahan yang berhubungan dengan sistem nilai sosial budaya, seperti sifat gorong-royong, tolong menolong, hormat-menghormati dan rasa persamaan. Dapat dikatakan bahwa aktivitas Alkhairaat dalam bidang pendidikan, terutama dakwah, semuanya bersumber dari nilai-nilai ajaran Islam.

Perlu diketahui, dampak dari kolonial

${ }_{28}$ Abuddin Nata, Kapita Selekta Pendidikan Islam, (Bandung: Angkasa 2003), hlm. 14
Belanda di Manado sejak abad ke-17 hingga abad ke-20, adalah lahirnya modernisasi. Modernisasi dibawa dan diperkenalkan oleh kolonialisme Barat, yang kedatangannya ke persada pertiwi ini bukan hanya mencari rempah-rempah, tetapi kemudian menguasai dan menjajah bangsa Indonesia, sekaligus menyiarkan agama Kristen (Protestan) dan Katolik. Oleh masyarakat Manado, modernisasi diidentikkan dengan perubahan gaya hidup yang kebarat-baratan. Bergaya Eropa selalu dikaitkan dengan Kristiani, dan pendidikan umum identik dengan pendidikan ala Eropa. ${ }^{29}$ Di sinilah dakwah dan pendidikan Alkhairaat berperan penting untuk memberikan nilai-nilai spiritual kepada masyarakat Islam di Manado, supaya dapat mengimbangi arus modernasi tersebut.

Oleh karena itu, Alkhairaat berusaha memberikan keseimbangan dalam ilmu pengetahuan agar masyarakat dan generasi Islam di Manado, tidak terjebak pada missi Zending yang sengaja menggaungkan budaya Barat yang cenderung mengutamakan kehidupan duniawi. Dalam praktiknya, pesantren Alkhairaat mengintegrasikan dua model pembelajaran (agama dan umum).

Sebagai organisasi sosial keagamaan yang tersebar secara masif di Sulawesi Utara, Perguruan Islam Alkhairat telah banyak melahirkan elit-elit baru yang tidak hanya terdiri dari tokoh-tokoh agama, tetapi juga tokoh-tokoh politik ${ }^{30}$, yang memberikan warna dalam dinamika masyarakat di

Ilham, "Agama, Perubahan Sosial dan Penggunaan Ruang di Manado, dari Kolonial ke Pasca Kolonial, dalam www.geocities. ws/konferensinasionalsejarah/ilham.pdf, diakses tanggal 19 Maret 2016.

30 Di antaranya ada K.H. Nurhasan (mantan Ketua Pengadilan Agama Manado), K.H. Sofyan Lahilote (mantan Ketua PA dan PTA Manado), K.H. Hasyim Arsyad (mantan Kasi Urusan Haji Depag Kodya Manado), K.H. Ust. Abd. Wahab Abd. Ghafur (Ketua MUI Sulut), H. Sarifa Fatmawati bin Syekh Abubakar (Aggota DPRD Kota Manado), dan masih banyak lagi yang lainnya. 
Manado. Modal sosial yang terbentuk dari madrasah-madrasah Alkhairat, telah menjadikan Perguruan Islam Alkhairat, sebagai sebuah kelompok kepentingan yang memiliki modal utama dibangunnya jaringan sosial dan politik Alkhairaat di tingkat lokal.

Berdasarkan uraian di atas, jelaslah bahwa melalui pendidikan dan dakwah Alkhairaat, perubahan masyarakat Islam di Manado, tidak terlepas dari ajaran Islam yang sangat mementingkan kemampuan mempergunakan kecerdasan (intelegensi). Sehingga tidak berlebihan jika dikatakan bahwa Alkhairaatmemiliki potensi yang besar, terutama jika dilihat dari para alumninya yang sukses menjadi tokoh-tokoh nasional. Keberhasilan Alkhairaat mencetak generasi gemilang membuktikan bahwa organisasi ini memiliki kelebihan dan potensi yang besar dalam pengembangan umat Islam di Manado.

\section{E. Kesimpulan}

Proses Islamisasi dan perkembangan Islam di Manado pada pertengahan abad ke20, tidak terlepas dari gerakan keagamaan Alkhairaat dalam bidang dakwah dan pendidikan selama tahun 1947-1960. Terbukti pertumbuhan madrasah-madrasah Diniyah di Manado baru terlihat pada pertengahan abad ke-20, ketika Lembaga Pendidikan Islam Alkhairaat mulai memasuki Sulawesi Utara. Tahun 1947 berdiri Madrasah Alkhairaat yang pertama di Kampung Arab, Manado. Pada perkembangan selanjutnya, Alkhairaat kemudian mendirikan sebuah pesantren di Komo Luar, Manado pada tahun 1960.

Dakwah Alkhairaat yang selalu berpegang pada prinsip-prinsip moderat dan toleran, membuat masyarakat di Manado yang majemukitu bersikap transparan dan antusias dalam menerima dan mengimplementasikan apa yang telah disampaikan. Usaha Alkhairaat untuk memberikan pencerahan dalam pembangunan spiritual, bagi terciptanya pola pikir, sistem pengetahuan, sistem sosial dan sistem perilaku umat Islam di Manado, sehingga berdampak pada perubahan sosial budaya masyarakat Islam Manado yang mencerminkan nilai-nilai agama. Ciri khas santri yang sederhana dan memiliki solidaritas yang tinggi yang melekat pada Abnaul Khairaat, juga telah berdampak pada perubahan yang berhubungan dengan sistem nilai sosialbudaya, seperti sifatgotong-royong, tolong-menolong, hormat-menghormati dan rasa persamaan. Sehingga tidak berlebihan jika dikatakan bahwa Alkhairaat memiliki potensi yang besar, terutama jika dilihat dari para alumninya yang sukses menjadi tokohtokoh nasional. Keberhasilan Alkhairaat mencetak generasi gemilang membuktikan bahwa organisasi ini memiliki kelebihan dan potensi yang besar dalam pengembangan umat Islam di Manado.

\section{DAFTAR PUSTAKA}

Amin, Basri, Islam di Utara Sulawesi: Sejarah, Tradisi dan Dinamikanya, Jakarta: Gramedia, 2005.

Az Miftah Faridl dalam A. Darun Setiady, Revitalisasi Peran PI dalam Pemberdayaan Umat, Bandung: Mizan, 2006iz, M. Ali, Ilmu Dakwah, Jakarta: Prenada Media, 2004.

Burke, Peter, Sejarah dan Teori Sosial, Cet. Ke2, Jakarta: Yayasan Obor Indonesia, 2003. Ilham, "Agama, Perubahan Sosial dan Penggunaan Ruang di Manado, dari Kolonial ke Pasca Kolonial, dalam www. geocities.ws/konferensinasionalsejarah/ ilham.pdf. Akses tanggal 19 Maret 2016. 
Khasanah, Siti Uswatun, Berdakwah dengan Jalan DebatAntara Muslim dan Non Muslim, Yogyakarta: STAIN Purwokerto Press \& Pustaka Pelajar, 2007.

Jumat, Gani, Nasionalisme Ulama: Pemikiran Politik Kebangsaan Sayyid Idrus Bin Salim Aljufry, 1891-1969, Jakarta: Kementrian Agama RI, 2012.

Khasanah, Siti Uswatun, Berdakwah dengan Jalan Debat Antara Muslim dan Non Muslim, Yogyakarta: STAIN Purwokerto Press \& Pustaka Pelajar, 2007.

Kuntowijoyo, Metodologi Sejarah, Edisi Kedua, Yogyakarta: Tiara Wacana, 2003.

L.A., Hadat, "Sejarah Islam di Sulawesi UtaraPart 4", dalam http://artfalsafah.blogspot. co.id/2013/05/html. Akses tanggal 30 Mei 2016.

Maftuh, "Lembaga Pendidikan Al-Khairiyah di Banten (1916-1942): Pendekatan Sejarah Sosial", Makalah Disertasi, Yogyakarta: PPS UIN Su-Ka Yogyakarta, 2015.
Mokalu, Benedicta J., “Gaya Hidup Prahara Karakter Kota Manado", Jurnal LPPM Bidang Ekososbudkum, Volume 1 Nomor 1 Tahun 2014.

Nasikun, Sistem Sosial Indonesia, Cet. Ke12, Jakarta: PT. Raja Grafindo Persada, Jakarta, 2003.

Nata, Abuddin, Kapita Selekta Pendidikan Islam, Bandung: Angkasa 2003.

Parengkuan, F.E.W., et al., Sejarah Kota Manado 1945-1979 (Jakarta: Depdikbud, 1986.

Romli, Asep Syamsul M., Komunikasi Dakwah: Pendekatan Praktis, Bandung: Mizan, 2014.

Setiady, A. Darun, Revitalisasi Peran PI dalam Pemberdayaan Umat. Bandung: Mizan, 2006.

Sumampouw, Nono Stevano Agustinus, "Menyatukan dan Memecah Belah: Wacana dan Praktek Identitas Sosial Orang Manado", Tesis, Yogyakarta: PPs Fakultas Ilmu Budaya UGM, 2013. 
JURNAL AQLAM -- Journal of Islam and Plurality-- Volume 2, Nomor 1, Juni 2017 